\title{
Not just another Pint! The Role of Emotion Induced by Music on the Consumer's Tasting Experience
}

\author{
Felipe Reinoso-Carvalho ${ }^{1,2, *}$, Silvana Dakduk ${ }^{1}$, Johan Wagemans ${ }^{2}$ and Charles Spence ${ }^{3}$ \\ ${ }^{1}$ Universidad de los Andes, School of Management, Universidad de los Andes, Calle 21 \# 1-20, \\ Edificio SD, Room SD-940, Bogotá, Colombia \\ ${ }^{2}$ KU Leuven, Brain and Cognition, University of Leuven (KU Leuven), Tiensestraat 102 - \\ box 3711, Leuven B-3000, Belgium \\ ${ }^{3}$ University of Oxford, Crossmodal Research Laboratory, University of Oxford, Anna Watts \\ Building, Oxford, OX2 6GG, UK
}

Received 5 December 2018; accepted 27 February 2019

\begin{abstract}
We introduce a novel methodology to assess the influence of the emotion induced by listening to music on the consumer's multisensory tasting experience. These crossmodal effects were analyzed when two contrasting music tracks (positive vs negative emotion) were presented to consumers while tasting beer. The results suggest that the emotional reactions triggered by the music influenced specific aspects of the multisensory tasting experience. Participants liked the beer more, and rated it as tasting sweeter, when listening to music associated with positive emotion. The same beer was rated as more bitter, with higher alcohol content, and as having more body, when the participants listened to music associated with negative emotion. Moreover, participants were willing to pay 7-8\% more for the beer that was tasted while they listened to positive music. This novel methodology was subsequently replicated with two different styles of beer. These results are discussed along with practical implications concerning the way in which music can add significant value to how a consumer responds to a brand.
\end{abstract}

\section{Keywords}

Beer, flavor, music, crossmodal correspondences, sensory marketing, multisensory

* To whom correspondence should be addressed. E-mail: f.reinosoc@uniandes.edu.co / f.sound@gmail.com 


\section{Introduction}

The multisensory nature of tasting has become increasingly clear to researchers in recent years (e.g., Auvray and Spence, 2008; Piqueras-Fiszman and Spence, 2016). As a matter of fact, renowned researchers from the field of marketing and consumer behavior have further enriched the discussion concerning how such novel insights (which are mostly being developed from the emerging cognitive neuroscience research on multisensory perception) can be brought to bear in the context of multisensory marketing and branding (e.g., Hultén, 2011; Krishna, 2012; Spence, 2019).

A growing body of research is now addressing the question of how what is heard influences the taste and flavor of foods and beverages (e.g., see Corr and Plagnol, 2018, Chapter 7). The research that has been conducted suggests that certain types of sounds and music can at least under the appropriate conditions - add significant value, and pleasure, to the eating/drinking experience, whereas the wrong music can also impair enjoyment and/or negatively affect the perceived value of such experiences (see Spence, 2017a, for a review). These studies have highlighted multisensory factors influencing the tasting experience and, to date, several different methods have been proposed to assess the effect of what we hear on what we taste (see Knöferle and Spence, 2012, for a review).

On the one hand, a spate of studies has highlighted the influence of the sound of the food itself, considering that this can add significant value (not to mention pleasure) to the consumer's overall multisensory eating/drinking experience (e.g., Spence et al., 2011). On the other hand, the sound and/or noise in those places in which we eat and drink - such as restaurants, airplanes - have been shown to dramatically affect the way in which we rate taste and flavor (Spence, 2012, 2014, 2017b; Spence et al., 2014).

The interactions between what we hear and what we eat/drink are particularly intriguing because it is not immediately obvious how, or even why, what we hear should influence what we taste, in those cases where the inputs from the various senses share nothing in common (as when listening to music or ambient soundscapes while eating/drinking). For instance, researchers have managed to isolate a number of specific sonic and musical parameters (such as pitch and instrumentation) that can be used to modify the tasting experience in predictable ways (e.g., Bronner et al., 2012; Crisinel and Spence, 2009, 2010, 2012; Crisinel et al., 2012; Reinoso 
Carvalho et al., 2016a). For example, Reinoso Carvalho et al. (2016a) demonstrated that people tend to associate sweet tastes with a higher pitch, whereas bitter tastes are usually associated with lower-pitched sounds instead (cf. Crisinel and Spence, 2010; Holt-Hansen, 1968, 1976; Rudmin and Cappelli, 1983).

Based on a growing list of such crossmodal associations, a range of taste/flavor-related music tracks have now been composed by artists, designers, sonic branding agencies, and researchers (e.g., Knoeferle et al., 2015; Mesz et al., 2011; Reinoso Carvalho et al., 2015a, 2016b; Wang and Spence, 2016). Some of these studies have further investigated the influence of this type of music on the way in which consumers judge different aspects of food (e.g., Reinoso Carvalho, 2015a, b; Wang and Spence, 2016), and drink (Reinoso Carvalho et al., 2016b; Spence et al., 2013; Wang and Spence, 2015a, b). For example, when it comes to alcoholic beverages, many of these assessments have demonstrated that sound can influence the consumer's evaluation of the taste/flavor of wine (North, 2012; Wang and Spence, 2015a), vodka (Wang and Spence, 2015b), beer (Reinoso Carvalho et al., 2016b), and whisky (Velasco et al., 2013). These results suggest that it is possible to produce music that can modulate people's taste and flavor judgments, using the aforementioned literature to underpin the sound stimuli so composed (see Note 1) or chosen (i.e., Hauck and Hecht, 2019; Knöferle and Spence, 2012; Reinoso Carvalho et al., 2015a, 2017). Of particular interest, both Crisinel et al. (2012) and Reinoso Carvalho et al. (2015a), have demonstrated that the consumer's judgment of the sweetness and bitterness of bittersweet foods (toffee and chocolate, respectively) can be modulated by means of customized 'sweet' and 'bitter' music tracks.

Looking for correspondences across the senses is not the only way in which to trigger associations between what we hear and taste. The fact that a consumer may — or may not — like the music that happens to be playing as part of a multisensory tasting experience, can also exert a significant influence over how the food/drink is evaluated. As such, the multisensory effects that may be observed could be mediated by personal preferences, and/or by the different emotional reactions that the music may induce (e.g., Kantono et al., 2016a; Wang and Spence, 2017, 2018; see Konečni, 2008, for an overview on how music can induce emotion). For instance, Wang and Spence (2017) suggested that certain wine-music pairings are rated as better matches than others, where they argued that wine-music associations are not arbitrary, and can be partially explained by emotional associations. 
Different studies have also addressed the question of how different types of sounds and music could influence the subjective value of tasting, potentially adding more pleasure to multisensory eating and drinking experiences (e.g., Fiegel et al., 2014; Kantono et al., 2016b; Reinoso Carvalho et al., 2015c). In particular, Fiegel et al. (2014) demonstrated that consumers tend to like the food significantly more while listening to jazz, as compared to hip-hop music. Note that this crossmodal influence of background music was only detected with chocolate (i.e., defined in this study as an emotional food), and not with the type of food pre-defined as nonemotional (bell pepper). In another of these studies, Reinoso Carvalho et al. (2015c) assessed whether consumers would agree that music and soundscapes enhanced their tasting experiences. The latter results revealed that not only did the customers report having a significantly better tasting experience when the sounds were presented as part of the food's identity, but they were also willing to pay up to $20 \%$ more for such multisensory tasting experiences (e.g., involving chocolate-music pairing), when compared to their willingness to pay for the food.

Different studies have assessed the particular influence of sound and music on the behavior of consumers. For instance, Biswas et al. (2019) recently reported that people tend to buy healthier food when there is quiet music/noise, as compared to loud background music/noise, or a silent control condition. Moreover, in this study, exposure to loud music/noise led to unhealthier food choices. Meanwhile, Sester et al. (2013) reported that the drinks selected by people can be influenced by the semantic, perceptual, or cognitive congruency between such drinks and immersive audiovisual projections of customised bar scenes. Another study assessed whether people's experience of a beer could be enriched by means of audiovisual information (see Reinoso Carvalho et al., 2016c). In the latter study, the presence vs absence of package labeling was manipulated in order to assess the potential effect of the beer's label, and its interaction with music, on the consumer's tasting experience (think of this experiment as an assessment of the potential usage of multisensory packaging solutions in order to, for example, increase brand loyalty). Results show that the beer-tasting experience was rated as more enjoyable with music than when the tasting was conducted in silence. Moreover, those who were familiar with the band who had composed the music track liked the beer more after having tasted it while listening to the music track, than those who knew the band, but only saw the label while tasting.

With the series of experiments reported in the present study, the question of whether 
different pieces of pre-recorded popular music could be used to modulate the way in which consumers judged different flavor and hedonic attributes of a tasting experience was analyzed. In order to set a suitable and robust methodology, six hypotheses were tested while addressing this question. In contrast to most of the previously-published findings (with a significant portion of them summarized above), here, the experimental music was not chosen based on crossmodal associations (Note 2) (cf. Reinoso Carvalho, 2015a, b, 2016b; Spence et al., 2013; Wang and Spence, 2015a, b, 2016), personal preferences (cf. Kantono et al., 2016a, b, c, 2018), or specific musical genre/style (cf. Fiegel et al., 2014). Whereas most of the existing findings surrounding this topic rely on classifying music based on auditory features (or on somewhat intuitive characterization/composition techniques), here, for the first time, the music was chosen solely on the basis of the emotional state that it would likely induce in consumers. In order to further innovate, and distinguish the way in which the auditory stimuli were selected, the selection of music tracks was validated using a well-standardized and robust method, the Positive and Negative Affection Score — PANAS (cf. Wang and Spence, 2018 [Note 3], where the music tracks were chosen based on their musical consonance vs dissonance; and Wang and Spence, 2017, where the different music tracks were chosen in terms of their tempo, mode, and variability of instrumentation). As far as we know, the PANAS has not been used to characterize music with taste/flavor correspondences in mind.

\subsection{Theoretical Framework}

In these experiments, it was decided to work with different beers as tasting stimuli. Beer is widely consumed at gatherings. Therefore, it is plausible to assume that music is commonly present in the background of people's everyday beer-tasting experiences, making such experiences most likely under the usual effect of auditory cues (Reinoso Carvalho et al., 2016b). As a general starting point, we assumed that music would somehow affect the evaluation of the tasting experience associated with a drink, as compared to drinking in silence (Bruner, 1990; Cohen et al., 2008; Hul et al., 1997).

1.1.1. Hypothesis 1-H1: Consumers experience a beer differently when there is music playing, as compared to drinking in silence 
We continue by focusing on the particular relationship between the beer and the music. In general, consumers tend to rely on their momentary emotional states while evaluating how good or bad — or perhaps how satisfying — an experience/service is (Schwarz and Clore, 1983). We assume, therefore, that some of the sensations and emotional responses elicited by listening to the different music would be transferred into two of the most important dimensions of a tasting experience: hedonic (Hypothesis 2 - H2), and sensory (Hypothesis 3 - H3; see Cheskin, 1972, for an early review of the notion of sensation transference) dimensions. For example, if participants were to prefer one music track over another, such differences might well be expected to affect the corresponding hedonic and sensory dimensions of the tasting experience (Kantono et al., 2016a, b, c). Therefore, if the experimental music were to trigger different emotional states (e.g., positive vs negative), we expected these to mediate the different hedonic aspects of the tasting experience (H2; cf. Noel and Dando, 2015).

1.1.2. Hypothesis 2 - H2: The hedonic experience associated with drinking a beer is affected by the emotions induced by the music that is heard during the tasting experience

Regarding potential effects that music could trigger on the sensory dimension of the tasting experience, music evoking a positive emotion has been shown to enhance the sweetness of different foods and drinks (H3; see Table 1 of Wang and Spence, 2018). For example, Kantono et al. (2016a) reported that chocolate ice cream is perceived as tasting sweeter when the music that is playing happens to be liked by the participants. The music tracks used in the aforementioned study were classified along a hedonic dimension, where the participants rated the available music tracks as being liked, neutral, or disliked. Wang and Spence (2018) have also demonstrated that, in the presence of external positively valenced audiovisual stimuli, juice is rated as tasting sweeter, when compared to the same drink when accompanied by negatively valenced external cues, regardless of whether the latter stimuli are visual or auditory.

1.1.3. Hypothesis 3 - H3: The sensory experience of a beer will be affected by the emotions induced by the music that is heard during the tasting experience 
It has also been suggested previously that, when looking to design positive experiences for customers, musical congruency in a service setting, or the congruency between the sensory dimensions of a scent and of music, in stores, induces lower arousal — which usually leads to higher pleasure - when compared to corresponding incongruent conditions (Demoulin, 2011; Fiegel et al., 2014; Mattila and Wirtz, 2001). In fact, North et al. (1997, 1999) reported that people can be influenced by certain music styles (i.e., varying in ethnicity) while choosing wine. Specifically, playing French music in a supermarket led to higher sales of French wine, while playing German music led to increased sales of German wine instead. More recently, Zellner et al. (2017) reported that students ordered more Spanish paella with Spanish music playing in the background of a canteen, as compared to another night where Italian music was played instead. Thus, it was hypothesized that a high level of congruency between the food/drink, and the music, would induce a low level of arousal in the multisensory tasting experience, potentially contributing to the overall perceived pleasantness.

1.1.4. Hypothesis 4 (H4): If the beer and the music do not match in some aspect (sensory or cognitive incongruence), induced arousal will be higher, which would lead to a less pleasant tasting experience, compared to congruent tasting conditions

While choosing and characterizing the different music tracks, even though there was no particular focus on their music genre/style, the implications of differences in genre/style - and how they may affect the study — were still considered (e.g., Areni and Kim, 1993; North et al., 1997, 1999). Previous reports have suggested that people may be willing to pay more for food and drink items when they are accompanied by music (especially in cases where the music is presented as part of a food/drink product's identity; see Reinoso Carvalho et al., 2015c, 2016c). Consequently, in the present study, we also decided to assess the participants' willingness to pay (WTP), based on the idea that the participants might be willing to pay significantly more, or less, for the food/drink, as a function of the music they heard during the tasting experience.

1.1.5. Hypothesis 5 (H5): Participants' WTP for a beer is affected by the music that is being played during the tasting experience (i.e., higher monetary value goes hand in hand with increased hedonic experience). 
It has often been noted how presenting contrasting combinations of multisensory stimuli typically leads to a more robust observation of crossmodal correspondence effects (i.e., comparing congruent vs incongruent pairings; see Spence, 2011), presumably because it draws attention to the relevant stimulus dimension (see Spence, in press). This effect was tested with two different experimental set-ups. In Experiment 1, the same drink was evaluated twice, once in the silent condition and another time while listening to one of the available music tracks. In Experiments 2 and 3, the participants evaluated the tasting experience while listening to two contrasting musical tracks (without a silent baseline condition).

1.1.6. Hypothesis 6 (H6): More robust crossmodal effects should be obtained when the beer is evaluated under the influence of two contrasting music tracks, as compared to evaluating the same beer under the influence of music vs in silence

Following the framework introduced here, one pre-test and three experiments were conducted. In the pre-test, a method of characterizing music based on its ability to evoke different emotions is proposed, using the PANAS scale. In Experiment 1, a multisensory behavioral test was conducted (using the music that was selected in the pre-test), where the participants compared their tasting experience while drinking the same beer twice, once listening to music and the other time in silence. Thereafter, it was decided to test $\mathrm{H} 6$ by eliminating the silent control condition of Experiment 1, and using a contrasting pair of music tracks that would evoke either positive or negative emotions (Experiment 2). The latter protocol was further replicated, but now using a very different type of beer, when compared to those used in Experiments 1 and 2, challenging the generalizability of the experimental approach (see Experiment 3).

\section{Pre-Test: Musical Selection}

The pre-test was designed to support the selection of music that would likely induce different emotional states in participants. The hypothesis of this pre-test was that participants would be able to differentiate music tracks that were chosen to resemble emotions with opposite valence (i.e., positive vs negative). 


\subsection{Materials and Methods}

\subsubsection{Participants}

A total of 263 participants between the ages of 17 and 75 years took part in the pre-test (52\% females, $48 \%$ males; mean age $=34$ years; $S D=13$ ). The majority were European residents (69.6\% Europeans; 22.4\% Americans; 5.7\% Asians; 1.1\% Oceanic; and 1.1\% Africans).

\subsubsection{Stimuli}

Music was selected that would either evoke positive or negative emotions. It was decided to prioritize strong emotional impact, and, envisioning the applicability potential of these ideas, to work with existing music that was available in the marketplace, and that had been composed by popular/professional musicians. Four music tracks were chosen: Two were chosen as music that would likely be associated with positive emotion (Positive 1 and Positive 2), and the other two as music that would be associated with negative emotion (Negative 1 and Negative 2). Table 1 summarizes the principal characteristics of each of the selected music tracks.

\section{Table 1.}

Main characteristics of the experimental music tracks analyzed in this pre-test

\begin{tabular}{|c|c|c|c|c|}
\hline Label & $\begin{array}{c}\text { Original } \\
\text { name of } \\
\text { music }\end{array}$ & $\begin{array}{c}\text { Mainly } \\
\text { compos } \\
\text { ed by }\end{array}$ & Technical Summary & Resemblance \\
\hline $\begin{array}{l}\text { Positi } \\
\text { ve } 1\end{array}$ & $\begin{array}{c}\text { Nocturne } \\
\text { Op. } 9 \\
\text { No. } 2\end{array}$ & Chopin & $\begin{array}{l}\text { E-flat major. This } \\
\text { contemplative piece is } \\
\text { in rounded binary form (A, A, } \\
\mathrm{B}, \mathrm{A}, \mathrm{B}, \mathrm{A} \text { ) with coda, } \mathrm{C} \text {, } \\
\text { which opens with a legato } \\
\text { melody, mostly played by } \\
\text { piano. The principal melody } \\
\text { repeats three times while, } \\
\text { progressively becoming more }\end{array}$ & $\begin{array}{l}\text { When thinking about Western } \\
\text { classical music, this piece is } \\
\text { usually regarded as embodying } \\
\text { music of the romantic era. }\end{array}$ \\
\hline
\end{tabular}




\begin{tabular}{|c|c|c|c|c|}
\hline & & & $\begin{array}{c}\text { elaborated, including } \\
\text { decorative tones and trills. } \\
\text { There is recurrent and } \\
\text { considerable rhythmic } \\
\text { freedom. }\end{array}$ & \\
\hline $\begin{array}{l}\text { Negat } \\
\text { ive } 1\end{array}$ & $\begin{array}{l}\text { Adagio } \\
\text { for } \\
\text { Strings }\end{array}$ & $\begin{array}{l}\text { Samuel } \\
\text { Barber }\end{array}$ & $\begin{array}{l}\text { Largely in the key of } \\
\mathrm{B} b \text { minor. It is an example } \\
\text { of arch-form-building on a } \\
\text { melody that first ascends and } \\
\text { then descends in stepwise } \\
\text { fashion. The lower strings } \\
\text { come in two beats after the } \\
\text { violins. In general, this } \\
\text { composition relies on a tense } \\
\text { melodic line with taut } \\
\text { harmonies. }\end{array}$ & $\begin{array}{l}\text { This music track is commonly } \\
\text { regarded as evoking very } \\
\text { negative emotions, and has } \\
\text { previously been rated cross- } \\
\text { culturally as one of the world's } \\
\text { most universally depressing } \\
\text { pieces of music (Huron, 2007). } \\
\text { It may be familiar to some as the } \\
\text { theme music from Oliver } \\
\text { Stone's Vietnam-era movie } \\
\text { "Platoon" (Note 4). }\end{array}$ \\
\hline $\begin{array}{l}\text { Positi } \\
\text { ve } 2\end{array}$ & $\begin{array}{c}\text { Porro } \\
\text { Sabanero }\end{array}$ & $\begin{array}{l}\text { Lucho } \\
\text { Bermud } \\
\text { ez }\end{array}$ & $\begin{array}{l}\text { The fastest in terms of tempo, } \\
\text { and probably the track with the } \\
\text { clearest folkloric connotation } \\
\text { (Note 5). This music track is } \\
\text { called "Porro Sabanero" (by } \\
\text { Lucho Bermudez). }\end{array}$ & $\begin{array}{l}\text { The 'porro' is a subgenre of the } \\
\text { Colombian Cumbia. Cumbia is } \\
\text { interpreted mostly by rich brass } \\
\text { bands or orchestras, which are } \\
\text { usually accompanied by a strong } \\
\text { and rigid rhythmical section } \\
\text { (Note 6). }\end{array}$ \\
\hline $\begin{array}{l}\text { Negat } \\
\text { ive } 2\end{array}$ & $\begin{array}{c}\text { Mors } \\
\text { Praematu } \\
\text { ra }\end{array}$ & $\begin{array}{l}\text { Jessica } \\
\text { Curry }\end{array}$ & $\begin{array}{l}\text { This is a music track that } \\
\text { mainly contains a baseline of } \\
\text { dissonant-legato orchestral } \\
\text { string and brass sections - in } \\
\text { the very low-frequency range, }\end{array}$ & $\begin{array}{l}\text { "Mors Praematura" is part of an } \\
\text { ambient soundtrack that is } \\
\text { supposed to support a narrative } \\
\text { of a horror-indie type of video- } \\
\text { game ("Amnesia: A Machine }\end{array}$ \\
\hline
\end{tabular}


when compared to the other

for Pigs").

three music tracks — along

with a high-pitched female

voice singing in lyric format.

These four pieces of music were cut to approximately one minute each. They were further mastered to roughly equal loudness. The music tracks, as they were played in the pre-test (and in the following experiments as well), can be heard at: https://tinyurl.com/sonictastemusicandemotions.

In terms of crossmodal correspondences (between sound/music, and basic taste attributes), and following the guidelines provided in Table 1, in Knöferle and Spence (2012), Positive 1 is the only music that may be partially regarded as 'sweet' (since this piece is mainly interpreted by piano melodies, although its frequency range does not fall into the purely 'sweet' category). Positive 2, and Negative 1, on the other hand, do not fall in any particular taste category. Moreover, Negative 2 may be regarded as a bitter type of music, due to its aggressive low-frequency baseline. However, the female voice does not allow this music to be framed as purely bitter either. In other words, even though two of the music tracks have clear elements that may position them as a 'sweet' (Positive 1), or 'bitter' (Negative 2), type of music, based on the literature on crossmodal correspondences, none of the four music tracks can be truly framed as purely associated with one particular taste note.

\subsection{Experimental Design and Procedure}

To validate the different emotions that the musical selection can evoke in participants, the PANAS scale was used (Crawford and Henry, 2004; Watson et al., 1988). This self-report questionnaire consists of 10-item scales designed to measure positive emotional reactions, and 10 -item scales to measure negative emotional reactions (i.e., there are 20 items/questions in total). Each answer is rated on a Likert-scale of 1 (not at all) to 5 (very much) - see worksheet 3.1, of Magyar-Moe, 2009, for the template on how the scales were constructed, and how they should be evaluated. For this pre-test, an electronic survey was distributed via the internet, 
globally, through the usage of different digital sources (e.g., social networks, different mailing lists, etc.). The recruitment process was based on convenience sampling, with some basic filters related to demographics, and technical equipment availability (e.g., the need of headphones or at least a good pair of loudspeakers) (Note 7).

This online survey was subdivided in three parts. First, the participants had to input basic personal data and accept the experimental conditions. They were then informed that they would listen to four musical tracks and, at the end of each one, they should answer a number of questions. In this part, they were also advised that, in order to participate in the survey, they should use headphones set at a comfortable listening level or at least a good pair of loudspeakers. In the second part of the study, the participants had to answer the full PANAS scale, after listening to each of the four music tracks (in total they answered the 20-items questionnaire four times; for each item, the maximum score available was 50, and the minimum 1). They were instructed to answer the questionnaires in terms of how each of the music tracks made them feel. In the third and final part of the study, the participants had to rank the four music tracks in order of preference.

Envisioning the fact that in the following multisensory experiments, the music tracks were to be analyzed in contrasting pairs (e.g., the effects of one positive track would be compared to those of one negative track, and so on), in the pre-test, the music tracks were presented in contrasting pairs as well, with the order of presentation as follows: Positive 1 vs Negative 1 (counterbalanced), and Positive 2 vs Negative 2 (counterbalanced). This means that the presentation of the four music stimuli was not fully randomized. Note that the order of presentation of the questions was fully randomized.

\subsection{Results}

All of the data analyses reported in the present study were conducted using the statistical package IBM SPSS Statistics (Version 21). Descriptive statistics were calculated following the scoring instructions of the PANAS questionnaire (see worksheet 3.1, of Magyar-Moe, 2009), for both the positive and negative emotional scales, and for each one of the music tracks. The higher positive score was for Positive 2 (Mean = 28.04), while the lower positive was for Negative 2 (Mean $=19.12)$. The highest negative score was for Negative $2($ Mean $=23.92)$, while the lowest scores were for Positive $1($ Mean $=12.53)$, and Positive $2($ Mean $=12.27)$. In general, Positive 1 
and Positive 2 clearly evoked more positive than negative emotional reactions, and were the two music tracks with the highest positive ratings. Negative 2 clearly revealed the opposite trend (see Table 2), and Negative 1 and 2 were the two music tracks with the highest negative ratings.

\section{Table 2.}

Descriptive statistics for positive and negative emotional scores for each music track. Means and corresponding SDs

\begin{tabular}{cccc}
\hline Emotion score & $\begin{array}{c}\text { Music } \\
\text { track }\end{array}$ & Mean $(\boldsymbol{M})$ & Std. deviation (SD) \\
\hline Positive score & Positive 1 & 25.02 & 7.43 \\
& Negative 1 & 22.06 & 8.01 \\
& Positive 2 & 28.04 & 8.24 \\
& Negative 2 & 19.12 & 6.81 \\
& & & 3.39 \\
Negative score & Positive 1 & 12.53 & 6.35 \\
& Negative 1 & 15.95 & 3.31 \\
& Positive 2 & 12.27 & 8.66 \\
\hline
\end{tabular}

Nevertheless, the results of Negative 1 are not conclusive enough. Although it was positioned more negatively than Positives 1 and 2, it had higher positive than negative scores.

Subsequently, in order to look for significant differences between the four music tracks, a RM-MANOVA was performed for the positive and negative scores, separately (Note 8). The results revealed a significant effect of the music tracks for both the positive $(F(3,786)=86.46, p$ $\left.<0.01, \eta^{2}=0.25\right)$, and for the negative $\left(F(3,786)=301.62, p<0.01, \eta^{2}=0.54\right)$ emotion scores. Subsequently, Bonferroni-corrected post-hoc analyses were conducted (Shaffer, 1995). In terms of positive emotion scores, significant differences were obtained between all of the average means of the music tracks ( $p<0.001$ for all comparisons). In terms of negative emotion scores, there were significant differences between all of the music tracks, except between Positive 1 and Positive 2 (see Table 3 for the comparisons). 


\section{Table 3.}

Differences between the means of the music tracks (asterisk ' $*$ ' indicates a significant difference at $p<0.001)$. In the positive emotion scores, we see that the differences between Positive 1 and Negative 2, between Positive 2 and Negative 2, and between Negative 1 and Positive 2 are more pronounced, as compared to the other mean differences. When it comes to the negative emotion scores, the differences between Positive 1 and Negative 2, and between the Positive 2 and Negative 2, stand out from the rest

\begin{tabular}{|c|c|c|c|c|c|c|}
\hline \multirow[t]{2}{*}{ Music track } & \multicolumn{3}{|c|}{ Positive emotion score } & \multicolumn{3}{|c|}{ Negative emotion score } \\
\hline & $\begin{array}{c}\text { Negative } \\
1\end{array}$ & $\begin{array}{c}\text { Positive } \\
2\end{array}$ & Negative 2 & $\begin{array}{c}\text { Negative } \\
1\end{array}$ & $\begin{array}{c}\text { Positive } \\
2\end{array}$ & $\begin{array}{c}\text { Negative } \\
2\end{array}$ \\
\hline Positive 1 & $2.88 *$ & $2.95^{*}$ & $5.92 *$ & $3.46 *$ & .23 & $11.41^{*}$ \\
\hline Negative 1 & & $5.84^{*}$ & $3.03 *$ & & $3.69 *$ & $7.95 *$ \\
\hline Positive 2 & & & $8.87 *$ & & & $11.64 *$ \\
\hline
\end{tabular}

Finally, the descriptive analysis regarding the way in which the participants ranked the music tracks in terms of their preference revealed that Positive 1 was principally ranked as the favorite track ( $45 \%$ of the time), Positive 2 was mostly ranked as the second favorite (32\% of the time), Negative 1 was mostly ranked as the third favorite ( $42 \%$ of the time), and Negative 2 was mostly ranked as the least favorite (59\% of the time).

In summary, three of the music tracks exhibited clear expected effects (Positive 1, Positive 2, Negative 2). The two positive music tracks were clearly ranked higher relative to the positive emotional PANAS score (see Tables 2 and 3). Regarding the corresponding negative emotional score, Negative 2 ranked higher by far. Interestingly, the usage of PANAS in the pretest was well-founded, since it allowed us not only to validate the choice of the music tracks, but also to find one music track that did not behave as expected. Even though Negative 1 was initially framed as an emotionally negative type of music, after the corresponding PANAS analysis, it did not present fully conclusive effects. Hence, it was decided not to use Negative 1 in the following experiments.

Having successfully selected the music, in the following experiments we went on to assess whether the emotional reactions induced by these selected music tracks would influence specific hedonic, sensory, preference, and WTP aspects of a consumer's tasting experience. 


\section{Experiment 1: Tasting Beer with Music vs in Silence}

In Experiment 1, the participants sampled a beer while listening to the music selected in the pretest, and evaluated their experience by means of a questionnaire. Here, we analyzed whether the emotional reactions induced by these musical selections would influence specific hedonic and sensory aspects of the beer tasting experience, as well as preference and WTP responses.

\subsection{Materials and Methods}

\subsubsection{Participants}

A total of 221 new participants took part in Experiment 1 (45\% females, 55\% males; $85 \%$ European residents). The mean age was 32 years (range 16-69 years, SD =13) (Note 9).

\subsubsection{Stimuli}

3.1.2.1. Flavor Stimuli. In Experiment 1, the beer used was 'Zinnebir' (produced by Brasserie de la Senne, a small Belgian brewery). It is a Belgian bitter-dry pale lager, with $6 \%$ alcohol (malty, with fine-salient bitterness (Note 10). The beers were served in normed $10 \mathrm{cl}$ samples (in order to avoid satiation), and in opaque black plastic cups (in order to prevent the participants from basing their responses on the beer's color).

3.1.2.1. Auditory Stimuli. Two of the three available music tracks were used: Positive 1 and Negative 2 (meaning one positive and one negative, respectively). All listening systems were calibrated to have approximately the same sound pressure level ( $L_{\text {eq } 30 \text { s }}$ of approximately $70+/-3$ dBA).

\subsection{Experimental Design and Procedure}

This experiment was conducted in an isolated area, where it was possible to have a fairly controlled environment during testing hours (Note 11). Each participant was seated in front of a computer screen with a pair of headphones, a computer mouse, and a keyboard with which to complete the survey. The music was presented over Sony MDRZX-310 headphones. The survey consisted of an electronic form containing three main steps. First, the participants were instructed 
to read and accept the conditions of the informed consent before entering their demographic details. In the second step, the participants tasted two identical samples of the same beer in two different trials, without being told that they were, in fact, tasting the same beer. The participants tasted the beer once while listening to either positive or negative music, and once in silence. After tasting each beer, they had to answer questions related to their hedonic and sensory experience. These answers were reported by means of 7-point rating scales. During the experiment itself, the beers were labeled as TK (when tasted while listening to music), and WD (when tasted in silence). The order in which the questions were presented was randomized. The order of the sound condition (music vs silent condition) was counterbalanced across participants as well. The third and final part of this questionnaire contained complementary multiple-choice and YES/NO questions related to the participants' beer preferences and price judgment. The presentation of these questions (and hence the corresponding choices of answers) was randomized (Note 12).

\subsection{Results}

Hedonic (e.g., liking of beer), sensory (e.g., flavor attributes of beer, such as sweetness, and alcohol strength), and other preference/consumer ratings (e.g., WTP) were analyzed as dependent variables. In general, the mean scores tended to be higher in the music condition than in the silent condition (see Table 4). In particular, the beer received higher ratings related to the flavor attributes of the beer (except for sweetness). For liking ratings, the average music score (negative + positive music effects) came close to the average of the silent condition score. For liking, the positive music received higher ratings than the negative music, with the silent condition in-between them.

A RM-ANOVA was further conducted for each of the two experimental conditions (silent vs positive, and silent vs negative), and for each scale, separately (Note 13). Bonferroni correction was applied for multiple comparisons (confidence interval, $\alpha=0.05 / 3=0.017$; see Cramer et al., 2016).

When asked how much they liked each beer, there were no differences observed. In terms of the perceived alcohol strength of the beer, a within-participants trend was observed (silent $M=4.03-$ music $M=4.24)\left[F(1,219)=5.40, p=0.021, \eta^{2}=0.024\right]$, suggesting that people may have rated 
the beer as tasting stronger (i.e., more alcoholic) while listening to music, regardless of the type of music (note that a similar result has been obtained previously in the case of fine wine tasted either with or without music; see Spence et al., 2013, Experiment 3). For ratings of the beer's body, there was a main effect for within-participants (silent $M=3.81$-music $M=4.07)[F(1,219)$ $\left.=8.22, p=0.005, \eta^{2}=0.036\right]$. The latter result means that in the music condition, and regardless of the type of music that the participants were listening to, the beer was rated as having more body when compared with the silent condition. No differences were found between the other sensory ratings of the beer (sweetness, bitterness, and sourness).

An additional independent $t$-test was conducted in order to assess how much the participants liked each of the music tracks. Significant differences were found between the music groups $[t(219)=11.11, p<0.001]$, where the participants liked the positive music more $(M=5.50)$ than the negative music $(M=3.31)$. Moreover, each participant had to choose whether they preferred to consume the beer while listening to music, or in silence. More participants preferred to consume the beer while listening to music, no matter whether the music was positive or negative (67\% and 55\%, respectively) (Note 14). The participants also rated how much they thought each of the music tracks matched the flavor of the beer. However, no significant effects were observed.

\section{Table 4.}

Means and SD of ratings related to the participants' beer evaluation, for hedonic and sensory ratings in Experiment 1. The first two rows are a comparison of the ratings of participants on the silent condition (first row), and music condition (second row; negative + positive music effects). The third and fourth rows are a comparison of the results of the music condition, disentagling negative vs positive effects. The results that are highlighted in bold show a significant difference between the two corresponding conditions.

\begin{tabular}{ccccccc}
\hline Group & Beer liking & Sweetness & Bitterness & Sourness & $\begin{array}{c}\text { Alcohol } \\
\text { strength }\end{array}$ & Body \\
\hline $\begin{array}{c}\text { Silent } \\
\text { condition }\end{array}$ & $4.30(1.57)$ & $2.81(1.37)$ & $4.64(1.34)$ & $3.55(1.44)$ & $4.03(1.25)$ & $\mathbf{3 . 8 1}(\mathbf{1 . 2 8})$ \\
$\begin{array}{c}\text { Music } \\
\text { condition }\end{array}$ & $4.34(1.66)$ & $2.71(1.30)$ & $4.80(1.37)$ & $3.65(1.57)$ & $4.24(1.25)$ & $\mathbf{4 . 0 7}(\mathbf{1 . 2 2})$ \\
& & & & & &
\end{tabular}




$\begin{array}{ccccccc}\begin{array}{c}\text { Negative } \\ \text { music }\end{array} & 4.18(1.48) & 2.65(1.25) & 4.73(1.29) & 3.59(1.54) & 4.11(1.19) & 3.86(1.31) \\ \begin{array}{c}\text { Positive } \\ \text { music }\end{array} & 4.49(1.74) & 2.89(1.34) & 4.71(1.46) & 3.61(1.61) & 4.17(1.32) & 4.03(1.11)\end{array}$

In summary, the results of Experiment 1 demonstrate that listening to the music exerted a few effects on people's rating of the beer. Here, the beer was rated as having more body (and was rated as potentially stronger in terms of alcohol content) when tasted with music, as compared with the ratings obtained in the silent condition (providing some support to H1).

\section{Experiment 2: Tasting Beer with Positive vs Negative Music}

In Experiment 2, the silent control condition was omitted and, instead, just the music having positive and negative emotion was presented to each participant (see H6). The participants were also subdivided into two groups. Each group now listened to two different pairs of contrasting music tracks. Moreover, a different beer was used, in order to investigate whether the different flavor attributes of the different beers would play a significant role in such multisensory effects.

\subsection{Materials and Methods}

\subsubsection{Participants}

A total of 154 new participants (54\% females, $46 \%$ males; 92\% European residents) took part in Experiment 2. The mean age was 33 years (range $17-69$ years, $\mathrm{SD}=13$ ).

\subsubsection{Stimuli}

4.1.2.1. Flavor Stimuli. The most popular and most consumed Belgian pale-lager beer $(5.2 \%$ alcohol) was used in Experiment 2 (Jupiler, produced by Anheuser-Busch InBev) (Note 15). 
4.1.2.2. Auditory Stimuli. Three music tracks from the pre-test were presented in contrasting pairs to the participants: Positive 1 vs Negative 2 (from now onwards, renamed simply as Negative), and Positive 2 vs Negative.

\subsection{Experimental Design and Procedure}

Briefly, the experimental design and procedure were the same as in Experiment 1, with a few variations, as follows:

1) The silent control condition was replaced by the presentation of two contrasting music tracks.

2) The beer was switched from Zinnebir to Jupiler.

3) The participant's WTP was assessed by means of a 7-point scale (presented in Euros).

4) Beer labels were WD (negative music), and TK (positive music).

\subsection{Results}

All of the average mean scores related to liking ratings were higher for the beer when combined with positive music than when combined with negative music. The same was also true in terms of sweetness ratings. By contrast, bitterness, alcohol strength, and body ratings revealed the opposite trend, with the negative music resulting in higher scores than the positive music (see Table 5).

A RM-ANOVA was conducted for each of the two experimental conditions (Positive $1+$ Negative; Positive $2+$ Negative), and for each scale, separately (positive music tracks together vs negative music track).

4.3.1. Hedonic Beer Evaluation. When asked how much they liked each beer, a main withinparticipants effect was observed $([\mathrm{F}(1,152)=19.343, \mathrm{p}<0.001, \eta 2=0.113])$, where participants reported liking the beer more while listening to the positive music $(M=4.81)$ whilst while listening to the negative music $(M=4.17)$.

4.3.2. Sensory Evaluation of the Beer (Flavor Attribute Ratings). A main within-participants effect on sweetness ratings was observed $\left[F(1,152)=27.22, p<0.001, \eta^{2}=0.152\right]$, with the 
participants rating the beer as tasting sweeter while listening to the positive music $(M=3.28)$ than while listening to the negative music ( $M=2.60$; see Fig. 1A).

A main within-participants effect was observed for bitterness (positive music $M=3.79$ negative music $\left.M=4.34 ;\left[F(1,152)=15.57, p<0.001, \eta^{2}=0.093\right]\right)$. Specifically, the participants rated the beer as tasting more bitter whilst listening to the negative as compared to the positive music. There was a main effect of group (Positive 1, $M=4$.28-Positive 2, $M=3.84$; $\left.\left[F(1,152)=7.02, p=0.009, \eta^{2}=0.044\right]\right)$, where the participants rated the beer as tasting more bitter while listening to Positive 1 than while listening to Positive 2 (see Fig. 1B).

In terms of the rated alcohol strength, there was a main within-participants effect (positive music $M=3.62-$ negative music $M=4.10 ;\left[F(1,152)=14.650, p<0.001, \eta^{2}=0.088\right]$ ), with participants rating the beer as tasting stronger while listening to the negative music, as compared to their ratings while listening to the positive music (see Fig. 1D).

A main within-participants effect for the ratings of the beer's body was also observed $\left[F(1,152)=11.496, p=0.001, \eta^{2}=0.070\right]$, with the beer being rated as having more body while the participants listened to the negative music $(M=4.06)$, when compared to the ratings related to the positive music $(M=3.66$ - see Fig. 1E). Summarizing, the obtained results related to the sensory evaluation of the beer supports H3. 

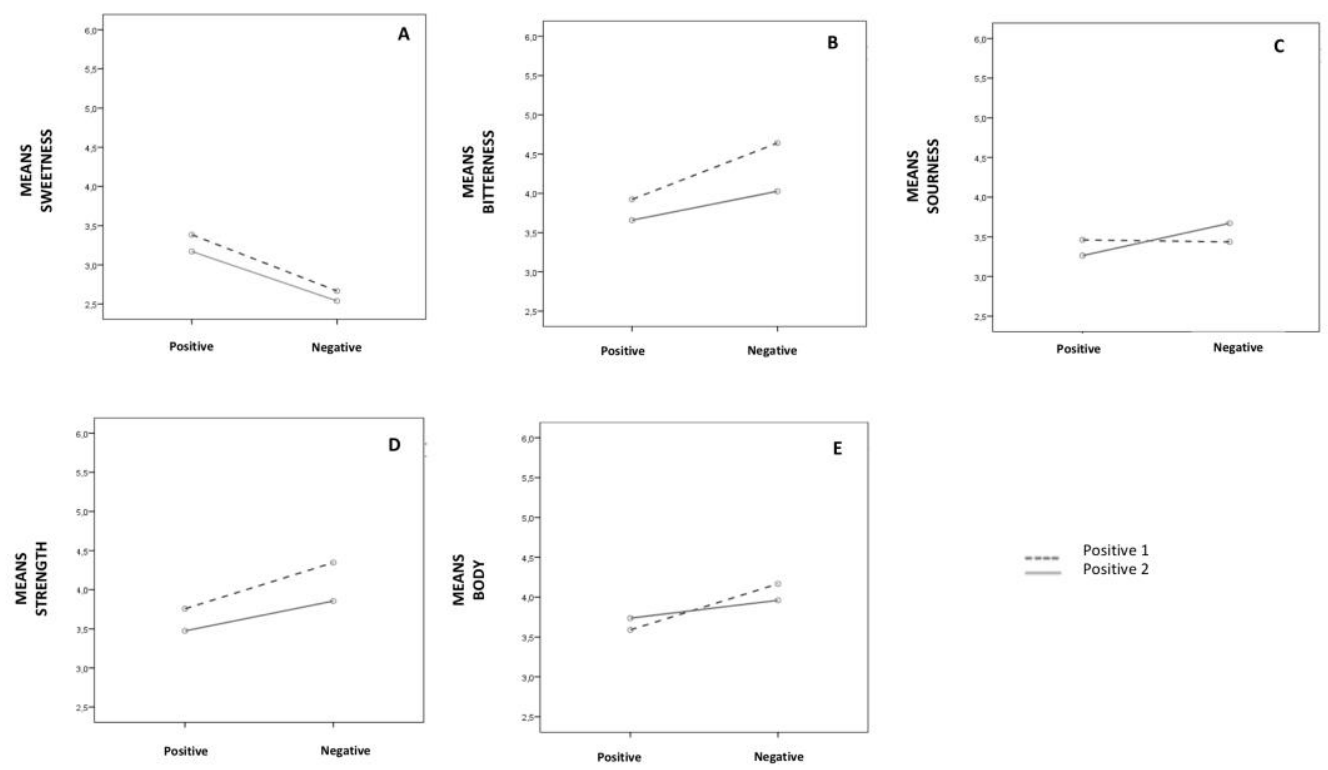

\begin{tabular}{cc}
---- & Positive 1 \\
\hline- & Positive 2
\end{tabular}

Figure 1. Interaction effect in repeated-measures analysis, for the sensory evaluation of the beer in Experiment 2. The $X$-axis represents the within-participants analysis (positive vs negative music). The $\mathrm{Y}$-axes represent the estimated marginal mean ratings of each flavor attribute - e.g., ' $A$ ' for sweetness, and ' $D$ ' for alcohol strength (with the full-scale going froM1 to 7). Positive 1 results are represented with dashed lines, whereas Positive 2 results are represented with solid lines.

\section{Table 5.}

Means and SD (SD values in parenthesis) of ratings related to the participants' beer evaluation for hedonic and sensory ratings in Experiment 2. The first two rows provide a comparison of the ratings of participants while listening to the Negative vs Positive (Positive $1+$ Positive 2) music. The third and fourth rows are a comparison of the ratings of participants while listening to the Positive 1 vs Positive 2 music. Results highlighted in bold show a significant difference between the two corresponding conditions

\begin{tabular}{ccccccc}
\hline $\begin{array}{c}\text { Music } \\
\text { condition }\end{array}$ & Liking & Sweetness & Bitterness & Sourness & $\begin{array}{c}\text { Alcohol } \\
\text { strength }\end{array}$ & Body \\
\hline Negative & $\mathbf{4 . 1 7}(\mathbf{1 . 5 5})$ & $\mathbf{2 . 6 0}(\mathbf{1 . 2 5})$ & $\mathbf{4 . 3 4}(\mathbf{1 . 3 3})$ & $3.55(1.53)$ & $\mathbf{4 . 1 0}(\mathbf{1 . 3 3})$ & $\mathbf{4 . 0 6 ( 1 . 3 8 )}$ \\
Positive & $\mathbf{4 . 8 1 ( 1 . 2 7 )}$ & $\mathbf{3 . 2 8}(\mathbf{1 . 3})$ & $\mathbf{3 . 7 9}(\mathbf{1 . 3 7})$ & $3.36(1.43)$ & $\mathbf{3 . 6 2}(\mathbf{1 . 3 5})$ & $\mathbf{3 . 6 6}(\mathbf{1 . 2 9})$
\end{tabular}


Positive $1 \quad 4.56(1.45) \quad 3.03(1.29) \quad 4.28(\mathbf{1 . 2 5}) \quad 3.45(1.39) \quad 4.05(1.37) \quad 3.88(1.38)$

$\begin{array}{lllllll}\text { Positive } 2 & 4.41(1.37) & 2.86(1.31) & \mathbf{3 . 8 4}(\mathbf{1 . 4 2}) & 3.46(1.57) & 3.66(1.29) & 3.85(1.25)\end{array}$

\subsubsection{Preference and WTP}

A main within-participants effect was observed for music preference $([\mathrm{F}(1,152)=170.19, \mathrm{p}<$ $0.001, \eta 2=0.528])$, with higher ratings for the positive music $(M=5.42)$ as compared to the negative music $(M=3.24)$. There was also a trend for an effect of group (Positive $1, M=4.51-$ Positive 2, $\mathrm{M}=4.15 ;[\mathrm{F}(1,152)=4.44, \mathrm{p}=0.037, \eta 2=0.028])$, suggesting that the participants preferred Positive 1 over Positive 2. An interaction effect between repeated measures (positive negative music) and group (Positive 1 - Positive 2) $[F(1,152)=6.94, p=0.009, \eta 2=0.044]$, was also observed, which confirms that there were clear differences on the way the participants appreciated each music track.

The participants reported liking the positive music more than the negative music. The participants were also asked to estimate their WTP for each of the two beers, in Euros. An additional dependent $t$-test was conducted to compare the WTP ratings for the TK beer (Jupiler combined with positive music), and for the WD (Jupiler combined with negative music). There were significant differences (Note 16) between both ratings $[t(153)=2.055, p \sim 0.004$; TK Beer $=4.29$ Euros; $\mathrm{WD}$ Beer $=4.00$ Euros], showing that the participants were willing to pay $7.25 \%$ more for the Jupiler beer, when tasted while listening the positive music, as compared to while listening to the negative music (supporting H5). The participants were further asked to choose which beer they preferred (TK, WD, or no preference). A higher percentage of participants preferred the TK beer (Jupiler combined with positive music), in both groups (Positive $1=58 \%$, Positive $2=49 \%$ ) (Note 17).

In summary, the results of Experiment 2 highlight more pronounced differences between the effects of the different music (positive vs negative) on the multisensory beer tasting experience, when compared to the effects that were reported in Experiment 1 (supporting H6). These results also suggest that the beer ratings may be under the influence of the different emotional reactions triggered by the music (the kind of influence that has been referred to as 'sensation transference' by Louis Cheskin, e.g., Cheskin, 1972). 


\section{Experiment 3}

In the final experiment, we decided to try and replicate the promising results obtained in Experiment 2 while changing the beer that the participants evaluated (e.g., Watson and Gunther, 2017; see Open Science Collaboration, 2015, on the importance of replicability in psychological — and related/applied — sciences).

\subsection{Participants}

A total of 157 new participants took part in this experiment (48\% females, 52\% males; $94 \%$ European residents). The mean age was 35 years (range 16-70 years, SD $=14$ ).

\subsection{Experimental Design and Procedure}

The experimental design and procedure of Experiment 3 were the same as for Experiment 2, except for the type of beer. Chimay Blue was chosen as the new beer because it is very different from the types of beer that were used in the previous experiments. This is a Belgian strong dark ale type of beer, with $9 \%$ alcohol. This dense beer has a strong caramel flavor, and a smooth palate sensation (Note 18).

\subsection{Results}

Reassuringly, in general, the results exhibit similar trends to those reported in Experiment 2 (except for the ratings of the beer's body). The ratings of liking and sweetness were higher for the positive music, when compared to the ratings given while listening to the negative music. On the other hand, bitterness, alcohol strength, and ratings of body were higher when it came to the ratings related to the negative music (see Table 6).

\subsubsection{Hedonic Evaluation of the Beer}

A main within-participants effect was observed for beer preference $[\mathrm{F}(1,155)=12.02, \mathrm{p}=0.001$, $\eta 2=0.072]$, with participants liking the beer more accompanied by the positive music $(\mathrm{M}=$ 4.79) than when accompanied by the negative music $(M=4.22)$. 


\subsubsection{Sensory Evaluation of the Beer}

A main within-participants effect on sweetness ratings was observed $[F(1,155)=13.01, p<$ $0.001, \eta^{2}=0.077$ ], with participants rating the beer as tasting sweeter while listening to the positive music $(M=3.67)$ as compared to the negative music $(M=3.19)-$ see Fig. 2A.

A main within-participants effect on bitterness ratings was observed $[F(1,155)=7.32, p$ $\left.=0.008, \eta^{2}=0.045\right]$ ), with the beer being rated as tasting more bitter while listening to the negative music $(M=4.25)$ as compared to the positive music $(M=3.88)-$ see Fig. $2 \mathrm{~B}$. For beer alcohol strength, a main effect for within-participants was observed $[F(1,155)=6.32, p=0.013$, $\left.\eta^{2}=0.039\right]$ ), with the participants rating this beer as tasting stronger while listening to the negative music $(M=4.50)$ as compared to the positive music $(M=4.20)-$ see Fig. 2D.
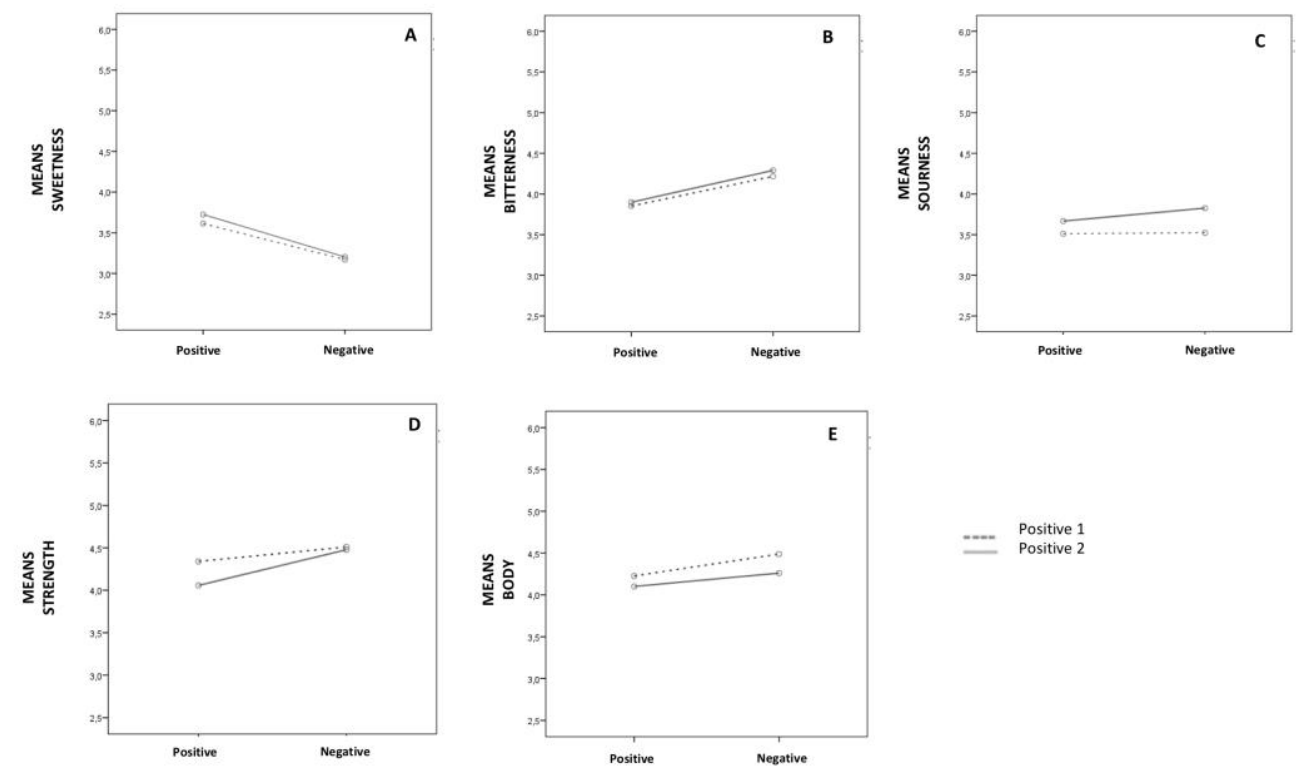

Positive 1
$-\quad$ Positive 2

Figure 2. Interaction effect in repeated measures analysis, for the sensory evaluation of the beer in Experiment 3. The $X$-axis represents the within-participants analysis (positive vs negative music). The Y-axes represent the estimated marginal mean ratings of each flavor attribute - e.g., 'A' for sweetness, and ' $D$ ' for alcohol strength (with the full-scale going froM1 to 7). Positive 1 results are represented with dashed lines, whereas Positive 2 results are represented with solid lines. 


\section{Table 6.}

Means and SD of ratings related to the participants' beer evaluation in Experiment 3. The first two rows are a comparison of the ratings of participants while listening to the Negative vs Positive (Positive $1+$ Positive 2) music conditions. The third and fourth rows provide a comparison of the ratings of participants while listening to the Positive 1 vs Positive 2 music conditions. Results highlighted in bold show a significant difference between the two corresponding conditions.

\begin{tabular}{ccccccc}
\hline $\begin{array}{c}\text { Music } \\
\text { condition }\end{array}$ & Liking & Sweetness & Bitterness & Sourness & $\begin{array}{c}\text { Alcohol } \\
\text { strength }\end{array}$ & Body \\
\hline Negative & $\mathbf{4 . 2 2}(\mathbf{1 . 5 1})$ & $\mathbf{3 . 1 9}(\mathbf{1 . 3 2})$ & $\mathbf{4 . 2 5}(\mathbf{1 . 3 4})$ & $3.67(1.37)$ & $\mathbf{4 . 5 0 ( 1 . 2 9 )}$ & $4.38(1.24)$ \\
Positive & $\mathbf{4 . 7 9}(\mathbf{1 . 6 3})$ & $\mathbf{3 . 6 7}(\mathbf{1 . 3 9})$ & $\mathbf{3 . 8 8}(\mathbf{1 . 3 7})$ & $3.59(1.49)$ & $\mathbf{4 . 2 0 ( 1 . 2 5 )}$ & $4.16(1.26)$ \\
& & & & & & \\
Positive 1 & $4.59(1.53)$ & $3.39(1.31)$ & $4.03(1.33)$ & $3.52(1.44)$ & $4.43(1.26)$ & $4.36(1.20)$ \\
Positive 2 & $4.40(1.60)$ & $3.46(1.43)$ & $4.09(2.12)$ & $3.75(1.54)$ & $4.27(1.29)$ & $4.18(1.32)$ \\
\hline
\end{tabular}

\subsubsection{Preference and WTP}

When asked how much they liked the music, a main within-participants effect was observed $[\mathrm{F}(1,155)=139.88, \mathrm{p}<0.001, \eta 2=0.474]$, with participants liking more the positive music $(\mathrm{M}=$ 5.32), when compared to the negative music $(M=3.22)$. There was also a main effect of group $[F(1,155)=7.33, p=0.008, \eta 2=0.045]$, with participants reporting that they liked Positive $1(\mathrm{M}$ =4.48) more than Positive $2(\mathrm{M}=3.99)$.

The corresponding WTP ratings show significant differences between the beers with a dependent $t$-test $[t(156)=2.17, p=0.031$; TK Beer $=4.29$ Euros; WD Beer $=4.00$ Euros $]$. The same difference in price was observed as in Experiment 2, where the participants were willing to pay $7.25 \%$ more for a beer while being tasted under the influence of the positive as compared to the negative music. A higher percentage of participants also preferred the TK beer (consumed with positive music) in both conditions (Positive $1=49 \%$, Positive $2=46 \%$ ) (Note 19).

In general, Experiment 3 works as a validation of the methodology proposed in 
Experiment 2. The results are very similar, except for the ratings of the beer's body. In Experiment 2, the Jupiler beer was rated as having significantly more body when tasted under the influence of the negative music, when compared to the ratings related to the positive music. In Experiment 3, the trends of body ratings were similar, but they failed to achieve statistical significance.

\section{General Discussion}

In these experiments, the effects of listening to positive vs negative emotion type of music on the consumer's tasting experience were studied. We investigated whether different pieces of popular music could be used to modulate the way in which consumers judge the experience of drinks (in this case, a beer). In terms of methodology, the principal novelty that this study brings to this topic is that the experimental music was not chosen based on the particular auditory features per se (Note 20), but rather — and solely — based on the emotional state that such music could induce on the consumers. In general, the results suggest that the emotional reactions triggered by the music came to influence specific aspects of the consumer's tasting experience. The results of Experiment 1 suggest that music can affect the way consumers rate certain aspects of a tasting experience (e.g., a beer's perceived body), when compared to drinking it in silence (regardless the type of music; H1). The results of Experiments 2 and 3 provided support to most of the research assessments tested here. In particular, it was shown that the hedonic (H2) and sensory (H3) experiences of a drink can be affected by the emotions induced by the music that is being played during the tasting experience (including a consumer's WTP for a drink - H5). Hence, Experiments 2 and 3 highlighted more pronounced differences between the effects of the different music (positive vs negative) on the multisensory tasting experience, when compared to the effects reported in Experiment 1 (giving support to H6, which states that more robust crossmodal effects tend to be reported when a tastant is evaluated under the influence of two contrasting music tracks, in comparison to evaluating the influence of one of the available music tracks vs in silence). Another complementary — and foremost - part of our research concerns the way the music should be chosen for this type of exercises. Here, we proposed the PANAS as a reliable way to validate such musical choices (at least, when it comes to understanding the emotional reactions that such music may elicit in people - e.g., positive or negative emotions). Importantly, the usage of PANAS in the pre-test was well founded, since it allowed us not only 
to validate the intuitive choice of the music tracks, but also to detect one music track that did not behave as expected.

As the main contribution of this article, we demonstrate that it is possible to implement a robust-replicable behavioral — and quantitative-based - methodology, using popular music (classified as evoking positive or negative emotions) to modulate the way in which consumers judge different aspects of a multisensory tasting experience (including sensory attributes of the beer, preference, liking ratings, and WTP). Such effects are clearly detected when two contrasting music tracks (in terms of positive vs negative emotions) are presented to the consumer, while, in this case, tasting the same beer. This novel methodology is unique because it allowed us, for the first time, to clearly disentangle the effects that the emotional mediation elicited by music is bringing to a tasting experience. All of this, regardless of how the music was composed, or characterized, in terms of its sonic/musical attributes.

In the pre-test, three out of the four music tracks tested had the expected effects (Positive 1, Positive 2, and Negative 2; see Table 3). The results related to Negative 1 were, however, not so clear-cut. The latter may have to do with the way that this music track had been cut. Perhaps the fragment of Negative 1 that was chosen for this exercise was not representative enough in terms of negativeness.

In Experiment 2, most of the hedonic, sensory, and consumer evaluations of the beer were clearly influenced by the different emotional reactions that the positive and negative music had on the participants' beer experience (see Fig. 1, and compare with the results of Experiment 1). The emotional reactions triggered by the music were somehow transferred into specific hedonic and sensory aspects of the beer-tasting experience. For instance, the beer was liked more, and it was judged as tasting sweeter while listening to the positive music (see H2 and H3). On the one hand, there is positive emotion induced by this music. On the other hand, the positive music was preferred over the negative music. Both aforementioned effects support a positive sensation transference (Cheskin, 1972), which boosted pleasure, thus most likely activating the reward system (by providing a more enjoyable tasting experience that, as a consequence, was rated as tasting 'sweeter') (Note 21).

Moreover, in Experiment 2, the participants also reported being willing to pay 7-8\% more for the same beer, while tasting it under the influence of the positive music, when compared to how much they were willing to pay under the influence of the negative music (see 
H5). This could also be related to the positive transference of sensations explained above.

In contrast, the beer was judged as tasting more bitter, as being more alcoholic, and as having more body, when experienced under the influence of the negative music (see H3). In this case, the negative music brought negative emotions to the tasting experience. It has been suggested that people in negative emotional states tend to search for more information in order to explain/resolve their mental condition, when compared to when in a more pleasant situation (Schwarz and Clore, 1983). Therefore, it could be argued that such a negative emotional state mostly resulted in less attention being devoted towards the music, and more attention being directed towards the most salient aspects of a beer's taste/flavor, such as the corresponding bitterness, and alcohol percentage (as in a kind of attentional shift/redirection effect; see Johnson and Proctor, 2004; Spence, 2014). Interestingly, the fact that the most salient flavor characteristics of the beer were enhanced by the mediation of the least preferred - and negatively-valenced type of — music, suggests that, depending on the desired outcomes, negativeness and incongruent multisensory associations may be as useful as the opposite — and perhaps more common - strategy.

The results of Experiment 3 replicated those of Experiment 2 while changing the beer evaluated by the participants. These new results were very similar to those reported in Experiment 2 (see Table 6; cf. Figs 1 vs 2). The only rating that did not achieve statistical significance in our final experiment was the difference in terms of the judgment of the beer's body (this difference achieved statistical significance in Experiment 2). The reason why this rating did not deliver the expected results might have to do with the fact that rating a drink's body tends to be a more complex type of evaluation for most people (e.g., when compared to judging its sweetness or bitterness), especially as far as naïve drinkers are concerned. In light of this finding, it may be interesting in future similar assessments to compare ratings between participants in terms of their level of experience/expertise with regard to the experimental tasting stimuli (e.g., in this case, their experience/expertise as beer drinkers).

The music tracks used in these experiments were musically and ethnically different. Obviously, they were also different in terms of their ability to evoke different emotions, as validated by the results of the pre-test. All of these differences triggered clear contrast in terms of musical preference. However, such dissimilarities did not result in a significant difference in terms of a better/worse match between the music and the beer(s) (Note 22). As such, with these 
results it is not possible to draw a conclusion regarding the importance of the potential arousal induced by the music in the beer experience (that is, there is no support for H4). Nevertheless, it can be argued that the effects tested here are mostly triggered by differences in valence, whereas potential arousal effects do not seem to be salient enough. The latter results would also appear to suggest that transfer effects are not generic, but they can be specific to valence, or arousal (cf. Fritz et al., 2017; Marin et al., 2017).

Summarizing briefly, a suitable methodology can emerge from the combination of the protocol presented in the pre-test with the protocol implemented in Experiments 2 and 3 (see H6). Such a novel methodology, as outlined here, can help better standardize the quantification of the effects that emotions induced by music can have on a consumer's drinking experience. We anticipate that the effects reported here with very different beers would be similar for different drinks, and perhaps even for different foods. On top of that, from this methodology, one could expect similar effects of other kinds of emotion-inducing stimuli. All of this could be further tested with different sensory/stimulatory combinations, such as touch, vision, while combined with different artistic expressions, and not only music.

\subsection{Implications for Practitioners}

Most brands tend to focus on the construction of a strong visual identity, without considering how, for example, sound and music can be used as a relevant attribute, with positive impact in a brand's awareness, and preference (Arora and Kumar, 2018). Hence, and given the results obtained here, we argue that music can be used to add value to the way in which a consumer responds to a brand (at least in the case of beers, as tested in this study). In this sense, the emotions induced by music can also potentially support a brand's positioning. For example, music that induces positive emotions could be an easy way to positively engage the consumer. On the other hand, and as mentioned above, people in negative emotional states tend to search for more information in order to explain their mental condition (Schwarz and Clore, 1983). Therefore, music that induces negative emotion should not be considered as necessarily having a negative impact on the experience of consumers. On the contrary, a positive experience can also arise for consumers, where negative music could be delivered as a type of music that induces more complex emotional reactions, which can result in more attention being paid to, for instance, 
the particular taste/flavor notes in a food/drink. Hence, those companies looking to explore different competitive positioning strategies based on positioning mapping techniques (e.g., sensory vs hedonic dimensions) could widen their scope of choices by focusing on more complex sonic identities as part of the brand experience (e.g., luxury branding/retailing). Overall, these results (which are mostly triggering effects in terms of consumption, and potentially choice) can also be taken to argue towards the usability of music as a tool to improve brand equity, which may ultimately help drive in increasing market value (Aaker and Biel, 2013).

Actually, global food and drink companies already seem to rely on these type of multisensory experiential design techniques as part of their branding strategies when, for example, developing events, or as support for advertising campaigns (e.g., Campari [Note 23], and Godiva [Note 24]). Recently, for instance, the city of Brussels (Belgium) funded a project entitled 'The Sound of Chocolate' (Note 25), where chocolate boxes were sold alongside music tracks designed to enhance certain aspects of the chocolate's taste and flavor. Besides proposing a new way of experiencing Belgian chocolate, through music, this project had the parallel aim of 'branding' Brussels as an innovative city. Similar multisensory experiences are also being offered by talented music composers, such as Maxime Goulet (Note 26). Ideas such as these may be useful when thinking of experiential retail. For instance, supermarkets may soon start to significantly reduce their physical spaces (following the expansion of e-commerce), and focus on more meaningful in-situ experiences. Consumers that decide to come personally to supermarkets could further engage through similar types of multisensory tasting experiences, while looking to learn about new products and their possibilities.

Nevertheless, the aforementioned existing examples (and a great portion of the existing scientific research surrounding this topic) rely mostly on classifying music based on auditory features (e.g., sonic seasoning), or on somewhat intuitive characterization/composition techniques. With these new results, we stress the importance of considering the emotional mediation of music in multisensory tasting experiences, along with the implications of the personal musical preferences of the consumers. These new results provide further support with respects to the need of more controlled and standardized multisensory food/drink-music pairing methods. As such, personal music playlists could be classified as a function of tastes/flavors, and potentially delivered to the end user by means of online streaming companies, such as Spotify, Apple Music, or Amazon music (Note 27). The further impact of streaming technology on 
retailing and consumer services may allow consumers to be aware, from their own musical preferences, which type of music would be better to listen to, while eating or drinking specific products (Reinoso Carvalho et al., 2016b; Velasco et al., 2016). Eventually, such multisensory experiences may also be explored along with novel media trends, such as 'mulsemedia' solutions, where multisensorial media delivery is being shown to outperform existing multimedia delivery solutions, in both, perceived quality, and enjoyment (Yuan et al., 2015).

\subsection{Limitations}

Music often provides changes in mood during an entire track. Therefore, it may be challenging to comprehend how the emotions prompted by a specific musical fragment will develop throughout a tasting experience that involves entire music tracks. In this sense, one should keep in mind that consumers also tend to rely on initial external cues while understanding the characteristics of flavor (and while keeping it homogeneous over time; Woods et al., 2010). Hence, it may be assumed that the judgment of the drink will most likely be set along with the first - or, perhaps, along with the highlighted - musical moment of the multisensory tasting experience.

When naïve consumers are asked to judge not-so-obvious flavor notes, such as the body of a beer, there is no certainty that such consumers are fully aware of what he/she is actually aiming for, especially when there is no reference. Perhaps one way to tackle the latter in future research would be to provide an initial reference point (e.g., start by rating the body of a neutral drink, such as water, prior the evaluation of the body of the experimental tasting stimuli).

The PANAS scale, as it is meant to be used, does not allow a more precise subdivision of the emotional reactions that the music is bringing into the tasting experiences conducted here (e.g., a clearer differentiation between, say, anger vs sadness, both different reactions that, nonetheless, fall within the same negative emotional dimension). Therefore, a way to complement this study comparing contrasting positive and negative emotional dimensions would be to compare positive (or negative) tracks that are somehow complementary/incompatible within their respective emotional dimensions (e.g., compare the effects of two sad music tracks, vs the effects of one sad vs one angry music track, and so on). With such type of comparisons, it 
may be possible to better disentangle the way in which emotions mediate such multisensory effects.

Finally, some may argue that these types of experimental design may be susceptible to demand, or social desirability, effects (see Rubin, 2016, for an understanding of demand effects, and/or Edwards, 1957, for an understanding on social desirability effects). Therefore, future assessments could install different ways to mitigate such potential confounds, for instance, by trying to 'camouflage' the hypothesis (e.g., 'mask' the connection between the music and the food/drink at stake).

\section{Author's Contributions}

FR, JW, and CS designed the study. FR led the data collection, and the selection/design of the different experimental stimuli. SD led the data analysis. All of the authors participated in the preparation of the manuscript and revised the final version of the manuscript.

\section{Funding}

FR and JW were supported by KU Leuven IOF internal funding scheme (C32/17/005). FR was also individually supported by Universidad de los Andes' FAPA internal funding scheme (FAPA N.32). JW was also supported by the Flemish Methusalem program (METH/14/02).

\section{Ethics Statement}

This study was carried out in accordance with the recommendations of the Social and Societal Ethics Committee at KU Leuven (SMEC, protocol registered as G-2015 07 281). All of the participants gave their written informed consent in accordance with the Declaration of Helsinki.

\section{Acknowledgements}

We would like to thank La Brasserie de la Senne for donating the beers used in Experiment 1. We would also like to acknowledge the support of Prof. Raymond van Ee during the first stage of the experimental design, and Dr. Pieter Moors for initial insights regarding the first batch of collected data. We would further like to thank François Nelissen, Elien Haentjens, Sarah Ahannach, Sam Van Broeck, Dr. Rebecca Chamberlain, Carlos Garcia, Midas Vanooteghem, Sarah Delcourt, Shyam Sekaran, Eleftheria Pistolas, Robin Panassie, Beyza Ozen, Aysun Duyar, Elisabeth Vanderhulst, Anurag Suri, Tereza Buckova, and Charlotte Buhre for assistance during 
data collection, and a very special thanks to the mim (Musical Instruments Museum Brussels), for hosting these experiments, and collaborating during the experimental days.

\section{Notes}

1. In the study reported by Reinoso Carvalho and colleagues (2015a), three music tracks were produced, one designed to be congruent with sweetness, another with bitterness, and the third lying somewhere in-between.

2. Also known as 'sonic seasoning'; e.g., music classified by its sonic and musical characteristics, where such characteristics can be associated with specific taste or flavor attributes (see Spence, 2017c).

3. Note that in this study musical dissonance was presented as an inducer of negative emotion, and vice versa. However, the effects reported were regardless of whether the stimuli were visual or auditory.

4. http://www.imdb.com/title/tt0091763/, retrieved April, 2018.

5. When thinking about ethnic congruency, it could be argued that this music track, as compared to the others used in this pre-test, could be rated as very incongruent when experienced with beer.

6. This genre is also regarded as being influenced by some of the Latin-American bands of the 1960's, and it is primarily meant for dancing.

7. The survey was provided in English, French, Portuguese, and Spanish. The only country where this survey could not be carried out was Germany, since they have strong playback filters that do not allow consumers to reproduce fragments of music (e.g., via Youtube, with Youtube being the streaming platform here used) that may have some relevance in terms of intellectual property disputes.

8. This statistical method was adopted given the fact that each participant evaluated the entire stimulus set, and more than one dependent variable was measured (Huberty and Olejnik, 2006).

9. The minimal legal age for drinking beer in Belgium, the country where these experiments took place, is 16 years of age. Moreover, in order to determine the sample size, a power analysis was performed based on Friedman's simplified determinations of statistical power (see Friedman, 1982, Table 1). Considering 95\% confidence $(\alpha=0.05)$, effect size of 0.25 , and a power effect of at least 0.8 , the suggested sample size would be 120 participants.

10. Extracted froMhttp://brasseriedelasenne.be/?portfolio=zinnebir, April, 2018.

11. There were four rectangular tables where eight participants could enter at the same time (two per table, with a total of eight computers running at once). The experience was individual, and the participants couldn't hear what others were listening at any point during the experiment. The natural light present in the experimental area was sufficient to provide an 'intimate' ambience. Therefore, artificial light was kept to a minimum. 
12. Together with the written guidelines concerning the experiment, at least one supervisor was present during the experimental process in order to provide guidance and support. Upon finishing the experiment, the participants were instructed to leave the room without discussing any details with the next group of participants. The experiment lasted for around 10 minutes. 13. Prior to this ANOVA, the assumption that the covariance matrices of the dependent variables were equal across groups was checked. This was obtained through a Box's Test of Equality of Covariance Matrices. As a measure of effect size, report generalized Partial Eta Squared $\left(\eta^{2}\right)$ was reported, as suggested by Levine and Hullett (2002).

14. There were no associations between experience preference and music groups $[C=0.127$, $\left.X^{2}(2)=3.616, p=0.164\right]$.

15. Retrieved froMhttps://www.beeradvocate.com/beer/profile/134/349/, April, 2018.

16. Significance at $p<0.005$.

17. The available choices were TK, WD, or no preference. There were no associations between the group and the preference for these ratings $\left[C=0.091, X^{2}(2)=1.274, p=0.529\right]$.

18. Retrieved froMhttps://www.beeradvocate.com/beer/profile/215/2512/, April 2018.

19. The available choices were TK, WD, or no preference. There were no associations between the group and the preference for these ratings $\left[C=0.146, X^{2}(2)=3.415, p=0.181\right]$. 20. E.g., music that is classified based on the sound characteristics, such as the frequency range, the timbres of the instruments incorporated, and how such sound characteristics can be congruently associated with flavor attributes.

21. https://www.npr.org/sections/thesalt/2014/01/15/262741403/why-sugar-makes-us-feelso-good, retrieved April 2018.

22. In Experiments 1-3, the participants rated how much they thought each of the music tracks matched the flavor of the beer. No effects were observed in terms of any of these results.

23. https://www.softecspa.com/en/portfolio/campari/, retrieved July, 2018.

24. https://www.moodiedavittreport.com/celebrating-90-years-godiva-hosts-multi-sensory-soiree-inbrussels/, retrieved July, 2018.

25. https://www.moodiedavittreport.com/celebrating-90-years-godiva-hosts-multi-sensory-soiree-inbrussels/, retrieved July, 2018.

26. $\quad$ www.thesoundofchocolate.be, retrieved July, 2018.

27. https://developer.spotify.com/; https://developer.apple.com/musickit/;

https://developer.amazon.com/; retrieved July, 2018.

\section{References}

Aaker, D. A., \& Biel, A. L. (2013). Brand equity \& advertising: advertising's role in building strong brands. Psychology Press, New York, NY, USA.

Areni, C. S. and Kim, D. (1993). The influence of background music on shopping behavior: Classical versus top-forty music in a wine store, Adv. Consum. Res. 20, 336-340. 
Arora, M. and Kumar, A. (2018). Consumer awareness towards brand equity, As. J. Manag. 9, 41-53.

Auvray, M. and Spence, C. (2008). The multisensory perception of flavor, Conscious. Cogn. 17, 1016-1031.

Biswas, D., Lund, K. and Szocs, C. (2019). Sounds like a healthy retail atmospheric strategy: Effects of ambient music and background noise on food sales, J. Acad. Mark. Sci. 47, 3755.

Bronner, K., Frieler, K., Bruhn, H., Hirt, R. and Piper, D. (2012). What is the sound of citrus? Research on the correspondences between the perception of sound and flavour, in: Proceedings of the 12th International Conference of Music Perception and Cognition (ICMPC) and the 8th Triennial Conference of the European Society for the Cognitive Sciences of Music (ESCOM). Thessaloniki, Greece, pp. 142-148.

Bruner, G. C. (1990). Music, mood, and marketing, J. Mark. 54, 94-104.

Cheskin, L. (1972). Marketing success: How to achieve it. Cahners Books, Boston, MA, USA:.

Cohen, J. B., Pham, M. T. and Andrade, E. B. (2008). The nature and role of affect in consumer behavior, in: C. P. Haugtvedt, P. Herr, and F. Kardes (Eds), Handbook of Consumer Psychology, pp. 297-348. Lawrence Erlbaum Associates, New York, NY, USA.

Corr, P. and Plagnol, A. (2018). Behavioral Economics: the Basics. London, UK: Routledge.

Cramer, A. O. J., van Ravenzwaaij, D., Matzke, D., Steingroever, H., Wetzels, R., Grasman, R. P. P. P., Waldorp, L. J. and Wagemakers, E.-J. (2016). Hidden multiplicity in exploratory multiway ANOVA: Prevalence and remedies, Psychon. Bull. Rev. 23, 640-647.

Crawford, J. R., and Henry, J. D. (2004). The Positive and Negative Affect Schedule (PANAS): Construct validity, measurement properties and normative data in a large non-clinical sample, Br. J. Clin. Psychol. 43, 245-265.

Crisinel, A.-S. and Spence, C. (2009). Implicit association between basic tastes and pitch, Neurosci Lett. 464, 39-42.

Crisinel, A.-S. and Spence, C. (2010). As bitter as a trombone: Synesthetic correspondences in nonsynesthetes between tastes/flavors and musical notes, Atten. Percept. Psychophys. 72, 1994-2002.

Crisinel, A.-S. and Spence, C. (2012). The impact of pleasantness ratings on crossmodal associations between food samples and musical notes, Food Qual. Pref. 24, 136-140. 
Crisinel, A.-S., Cosser, S., King, S., Jones, R., Petrie, J. and Spence, C. (2012). A bittersweet symphony: Systematically modulating the taste of food by changing the sonic properties of the soundtrack playing in the background, Food Qual. Pref. 24, 201-204.

Demoulin, N. T. M. (2011). Music congruency in a service setting: The mediating role of emotional and cognitive responses, J. Retail. Consum. Serv. 18, 10-18.

Edwards, A. L. (1957). The Social Desirability Variable in Personality Assessment and Research. Dryden Press, Ft Worth, TX, USA.

Fiegel, A., Meullenet, J.-F., Harrington, R. J., Humble, R. and Seo, H.-S. (2014). Background music genre can modulate flavor pleasantness and overall impression of food stimuli, Appetite 76, 144-152.

Fritz, T. H., Brummerloh, B., Urquijo, M., Wegner, K., Reimer, E., Gutekunst, S., Scheinder, L., Smallwood, J. and Villringer, A. (2017). Blame it on the bossa nova: Transfer of perceived sexiness from music to touch, J. Exp. Psychol. Gen. 146, 1360-1365.

Hauck, P. and Hecht, H. (2019). Having a drink with Tchaikovsky: The crossmodal influence of background music on the taste of beverages, Multisens. Res. 32(1), 1-24.

Holt-Hansen, K. (1968). Taste and pitch, Percept. Mot. Skills 27, 59-68.

Holt-Hansen, K. (1976). Extraordinary experiences during cross-modal perception, Percept. Mot. Skills 43, 1023-1027.

Huberty, C. J. and Olejnik, S. (2006). Applied MANOVA and discriminant analysis. John Wiley and Sons, Hoboken, NJ, USA.

Hultén, B. (2011). Sensory marketing: The multi-sensory brand-experience concept, Eur. Bus. Rev. 23, 256-273.

Huron, D. (2007). Sweet Anticipation: Music and the Psychology of Expectation. MIT Press, Cambridge, MA, USA.

Johnson, A. and Proctor, R. W. (2004). Attention: Theory and Practice. Sage, Thousand Oaks, CA, USA.

Kantono, K., Hamid, N., Shepherd, D., Lin, Y. H. T., Yakuncheva, S., Yoo, M. J. Y., Grazioli, G. and Carr, B. T. (2016b). The influence of auditory and visual stimuli on the pleasantness of chocolate gelati, Food Qual. Pref. 53, 9-18.

Kantono, K., Hamid, N., Shepherd, D., Yoo, M. J. Y., Grazioli, G. and Carr, B. T. (2016a). Listening to music can influence hedonic and sensory perceptions of gelati, Appetite 100, 
244-255.

Kantono, K., Hamid, N., Shepherd, D., Yoo, M. J. Y., Carr, B. T. and Grazioli, G. (2016c). The effect of background music on food pleasantness ratings, Psychol. Music 44, 1111-1125.

Kantono, K., Hamid, N., Shepherd, D., Lin, Y. H. T., Brard, C., Grazioli, G. and Carr, B. T. (2018). The effect of music on gelato perception in different eating contexts, Food Res. Int. 113, 43-56.

Knöferle, K. and Spence, C. (2012). Crossmodal correspondences between sounds and tastes, Psychon. Bull. Rev. 19, 1-15.

Knoeferle, K. M., Woods, A., Käppler, F. and Spence, C. (2015). That sounds sweet: Using cross- modal correspondences to communicate gustatory attributes, Psychol. Mark. 32, $107-120$.

Konečni, V. J. (2008). Does music induce emotion? A theoretical and methodological analysis, Psychol. Aesthet. Creat. Arts 2, 115-129.

Krishna, A. (2012). An integrative review of sensory marketing: Engaging the senses to affect perception, judgment and behavior, J. Consum. Psychol. 22, 332-351.

Levine, T. R. and Hullett, C. R. (2002). Eta squared, partial eta squared and the misreporting of effect size in communication research, Hum. Commun. Res. 28, 612-625.

Magyar-Moe, J. L. (2009). Therapist's Guide to Positive Psychological Interventions. Burlington, MA: Academic Press.

Marin, M. M., Schober, R., Gingras, B. and Leder, H. (2017). Misattribution of musical arousal increases sexual attraction towards opposite-sex faces in females, PloS One 12, e0183531. doi: 10.1371/journal.pone.0183531

Mattila, A. S. and Wirtz, J. (2001). Congruency of scent and music as a driver of in-store evaluations and behavior, J. Retail. 77, 273-289.

Mesz, B., Trevisan, M. A., \& Sigman, M. (2011). The taste of music. Perception, 40(2), 209219.

Noel, C. and Dando, R. (2015). The effect of emotional state on taste perception, Appetite 95, 89-95.

North, A. C. (2012). The effect of background music on the taste of wine, Br. J. Psychol. 103, 293-301. 
North, A. C., Hargreaves, D. J. and McKendrick, J. (1997). In-store music affects product choice, Nature 390, 132.

North, A. C., Hargreaves, D. J, and McKendrick, J. (1999). The influence of in-store music on wine selections, J. Appl. Psychol. 84, 271-276.

Open Science Collaboration (2015). Estimating the reproducibility of psychological science, Science 349, aac4716. doi: 10.1126/science.aac4716

Piqueras-Fiszman, B. and Spence, C. (Eds). (2016). Multisensory Flavor Perception: From Fundamental Neuroscience through to the Marketplace. Woodhead Publishing, London, UK.

Reinoso Carvalho, F., Van Ee, R., Rychtarikova, M., Touhafi, A., Steenhaut, K., Persoone, D., Spence, C. and Leman, M. (2015a). Does music influence the multisensory tasting experience? J. Sens. Stud. 30, 404-412.

Reinoso Carvalho, F., Van Ee, R., Touhafi, A., Steenhaut, K. and Rychtarikova, M. (2015b). Assessing multisensory tasting experiences by means of customized soundscapes, in: Euronoise 2015, Maastricht, The Netherlands, Vol. 1, pp. 739-744.

Reinoso Carvalho, F., Van Ee, R., Rychtarikova, M., Touhafi, A., Steenhaut, K., Persoone, D. and Spence, C. (2015c). Using sound-taste correspondences to enhance the subjective value of tasting experiences, Front. Psychol. 6, 1309. doi: 10.3389/fpsyg.2015.01309

Reinoso Carvalho, F., Wang, Q. (J.), de Causmaecker, B., Steenhaut, K., van Ee, R. and Spence, C. (2016a). Tune that beer! Listening for the pitch of beer, Beverages 2, 31. doi: 10.3390/beverages 2040031

Reinoso Carvalho, F., Steenhaut, K., van Ee, R., Touhafi, A. and Velasco, C. (2016b). Soundenhanced gustatory experiences and technology, in: Proceedings of the 1st Workshop on Multi-sensorial Approaches to Human-Food Interaction, Tokyo, Japan, art. 5.

Reinoso Carvalho, F., Velasco, C., van Ee, R., Leboeuf, Y. and Spence, C. (2016c). Music influences hedonic and taste ratings in beer, Front. Psychol. 7, 636. doi: 10.3389/fpsyg.2016.00636

Reinoso Carvalho, F., Wang, Q. J., Van Ee, R. and Spence, C. (2016d). The influence of soundscapes on the perception and evaluation of beers, Food Qual. Pref. 52, 32-41.

Reinoso Carvalho, F., Wang, Q. (J.), van Ee, R., Persoone, D. and Spence, C. (2017). "Smooth operator": Music modulates the perceived creaminess, sweetness, and bitterness of 
chocolate, Appetite 108, 383-390.

Rubin, M. (2016). The Perceived Awareness of the Research Hypothesis Scale: Assessing the influence of demand characteristics, Figshare. doi: 10.6084/m9.figshare.4315778

Rudmin, F. and Cappelli, M. (1983). Tone-taste synesthesia: A replication, Percept. Mot. Skills 56, 118.

Schwarz, N. and Clore, G. L. (1983). Mood, misattribution, and judgments of well-being: Informative and directive functions of affective states, J. Personal. Soc. Psychol. 45, $513-523$.

Sester, C., Deroy, O., Sutan, A., Galia, F., Desmarchelier, J.-F., Valentin, D. and Dacremont, C. (2013). "Having a drink in a bar": An immersive approach to explore the effects of context on drink choice, Food Qual. Pref. 28, 23-31.

Shaffer, J. P. (1995). Multiple hypothesis testing, Annu. Rev. Psychol. 46, 561-584.

Spence, C. (2011). Crossmodal correspondences: A tutorial review, Atten. Percept. Psychophys. 73, 971-995.

Spence, C. (2012). Auditory contributions to flavour perception and feeding behaviour, Physiol. Behav. 107, 505-515.

Spence, C. (2014). Noise and its impact on the perception of food and drink, Flavour 3, 9. doi: 10.1186/2044-7248-3-9

Spence, C. (2017a). Gastrophysics: The new science of eating. London, UK: Viking Penguin.

Spence, C. (2017b). Tasting in the air: A review, Int. J. Gastron. Food Sci. 9, 10-15.

Spence, C. (2017c). Sonic seasoning, in: L. Minsky and C. Fahey (Eds), Audio Branding: Using Sound to Build your Brand, pp. 52-58, Kogan Page, London, UK.

Spence, C. (2019). Multisensory experiential wine marketing, Food Qual. Pref. 71, 106-116.

Spence, C. (in press). On the relative nature of (pitch-based) crossmodal correspondences. Multisens. Res.

Spence, C., Shankar, M. U. and Blumenthal, H. (2011). 'Sound bites': Auditory contributions to the perception and consumption of food and drink, in: F. Bacci and D. Melcher (Eds), Art and the Senses, pp. 207-238, Oxford University Press, New York, NY, USA.

Spence, C., Richards, L., Kjellin, E., Huhnt, A.-M., Daskal, V., Scheybeler, A., Velasco, C. and Deroy, O. (2013). Looking for crossmodal correspondences between classical music and fine wine, Flavour 2, 29. doi: 10.1186/2044-7248-2-29 
Spence, C., Michel, C., and Smith, B. (2014). Airplane noise and the taste of umami, Flavour 3, 2. doi: $10.1186 / 044-7248-3-2$

Velasco, C., Carvalho, F. R., Petit, O. and Nijholt, A. (2016). A multisensory approach for the design of food and drink enhancing sonic systems, in: Proceedings of the 1st Workshop on Multi-sensorial Approaches to Human-Food Interaction, Tokyo, Japan, p. 7.

Velasco, C., Jones, R., King, S. and Spence, C. (2013). Assessing the influence of the multisensory environment on the whisky drinking experience, Flavour 2, 23. doi: $10.1186 / 2044-7248-2-23$

Wang, Q. (J.) and Spence, C. (2015a). Assessing the effect of musical congruency on wine tasting in a live performance setting, $i$-Perception 6, 2041669515593027. doi: $10.1177 / 2041669515593027$

Wang, Q. J. and Spence, C. (2015b). Assessing the influence of the multisensory atmosphere on the taste of vodka, Beverages 1, 204-217.

Wang, Q. (J.) and Spence, C. (2016). "Striking a sour note": Assessing the influence of consonant and dissonant music on taste perception, Multisens. Res. 29, 195-208.

Wang, Q. (J.) and Spence, C. (2017). Assessing the role of emotional associations in mediating crossmodal correspondences between classical music and red wine, Beverages 3, 1. doi: 10.3390/beverages3010001

Wang, Q. (J.) and Spence, C. (2018). "A sweet smile": the modulatory role of emotion in how extrinsic factors influence taste evaluation, Cogn. Emot. 32, 1052-1061.

Watson, D., Clark, L. A. and Tellegen, A. (1988). Development and validation of brief measures of positive and negative affect: The PANAS scales, J. Personal. Soc. Psychol. 54, 10631070.

Watson, Q. J. and Gunter, K. L. (2017). Trombones elicit bitter more strongly than do clarinets: a partial replication of three studies of Crisinel and Spence, Multisens. Res. 30, 321-335.

Woods, A. T., Poliakoff, E., Lloyd, D. M., Dijksterhuis, G. B. and Thomas, A. (2010). Flavor expectation: the effects of assuming homogeneity on drink perception, Chemosens. Percept. 3, 174-181.

Yuan, Z., Ghinea, G. and Muntean, G.-M. (2015). Beyond multimedia adaptation: Quality of experience-aware multi-sensorial media delivery, IEEE Trans. Multimedia, 17, 104-117. 
Zellner, D., Geller, T., Lyons, S., Pyper, A. and Riaz, K. (2017). Ethnic congruence of music and food affects food selection but not liking, Food Qual. Pref. 56, 126-129. 